\title{
When Sport Event Work Stopped: Exposure of Sport Event Labor Precarity by the COVID-19 Pandemic
}

\author{
R. Dale Sheptak Jr. \\ Brian E. Menaker \\ Baldwin Wallace University \\ Texas A\&M University—Kingsville
}

The COVID-19 pandemic of 2020 has exposed major weaknesses in economic, governmental, and social structures that many have taken for granted in everyday life. The sport industry, which has gained unprecedented popularity in recent decades, is no exception. Decisions, driven in response to the COVID-19 outbreak, to suspend play in major sports leagues across the globe have exposed the precarious nature of the work situation that hourly event workers find themselves in. As the games stopped, so did the earnings of workers who impact essential aspects of the sport spectators' experience. These workers include the part-time front of house staff for public assembly facilities, including ushers, concessions workers, ticket takers, and security personnel. This essay, drawing on ideas from C.W. Mills, Arne Kalleberg, and Guy Standing, will examine the impact of the pandemic on the employment of these workers by looking at the state of labor associated with sport and sports events. Furthermore, the essay will explore the challenges facing a class of workers who depend on numerous parttime or seasonal sports event jobs to scrape together an existence when sport suddenly stops. Finally, the essay will address the potential aftereffects of the COVID-19 pandemic on sport labor and consider how sport work could change as a result. This scholarly commentary lays the groundwork for further study and analysis of an important, yet rarely remarked on, aspect of employment morality and sport labor studies.

Keywords: employment, event management, precarious labor, sport jobs, workers

The COVID-19 pandemic of 2020 has led to a collapse in the economic, governmental, and social structures that have defined globalized society in the $21 \mathrm{st}$ century. The hit to the labor market may be the most striking. In the first 6 weeks of the pandemic-forced restrictions, more than 30 million Americans filed for unemployment benefits (Swartz, Hsu, \& Cohen, 2020), many of those in service 
industry jobs. In addition, the U.S. economy contracted $4.8 \%$ in the first quarter of 2020, the worst contraction of the economy since the 2008 Great Recession (Casselman, 2020). The sports industry in the United States has not been immune to the impact of the pandemic. Like many service sector businesses, the industry has effectively shut down, and work associated with sport has ceased while the games are on hold. Historically, issues with laborers who support sporting events have been largely ignored in the media and sport management literature. However, recent decisions driven in response to the COVID-19 outbreak to suspend play in major leagues has thrust the plight of sport event and venue workers, albeit briefly, to the forefront of media coverage. Prime-time news segments exposed the precarious nature of the work situation that hourly event and venue workers found themselves in. Essentially, when the games stopped, so did the work.

The five major leagues in the United States, Major League Baseball (MLB), Major League Soccer (MLS), National Basketball Association (NBA), National Football League, and National Hockey League, had varied and often decentralized responses to worker issues due to the shutdown. Initially, uplifting support of sports event workers poured in from owners and many others in professional sports who were in better financial shape than the event workers. Professional athletes, primarily basketball players including Kevin Love, Zion Williamson, and Giannis Antetokounmpo, responded immediately with altruistic commitments to help offset any hardships and cover hourly workers' pay. Likewise, three major sport franchise owners, Mark Cuban (Dallas Mavericks/NBA), Dan Gilbert (Cleveland Cavaliers/NBA), and Arthur Blank (Atlanta United/MLS), acted quickly and pledged to pay hourly workers through the shutdown. In the month that followed, the sports world has seen mixed responses from organizations and owners. The 30 MLB teams pledged \$1 million to their workers. The San Diego Padres set aside $\$ 200,000$ of it to pay contract workers who offer their services through third parties. In addition, the owner of the Barclay's Center, which hosts approximately 200 events each year and is home to the NBA Brooklyn Nets, set up a \$6 million fund to support workers through the end of May. However, reports have shown that most of the teams that pledged financial help to their event workers have come up short, with contract workers falling through the cracks in the purported safety net (Armour, Axon, Berkowitz, \& Schade, 2020).

While the impact of the pandemic on sport work is clear in media coverage, the fundamental depth of the problem has remained unexplored. The pandemic has exposed, to those willing to look beneath the surface, the precarious nature of the sport workers' positions. The phenomenon of precarious work or labor is not unique to sport; much has been written on the state of precarious labor in other industries, with little attention ever given to the part-time and seasonal workers who are the engine behind most major sporting events. The atypical nature of sport event work and the categorization of those workers has been noted (see McLeod, Holden, Hawzen, \& Chahardovali, 2019). Their situation, their way of life, the precarious existence that they endure is worthy of attention, and the forced shutdown of sport exposed the temporary and often exploitative arrangement of sport events and venues work. This essay will attempt to examine the state of labor associated with this particular type of vocation (i.e., seasonal, hourly, part time) in the sport and sports events industry due to the current pandemic. It is prudent to recognize that there is great disparity in the type and scope of labor 
models employed in sport and events around the globe, and it would be difficult to generalize on the impact of the pandemic. As such, the focus of this commentary is on the sport and events industry in the United States. Furthermore, the approach taken is largely anecdotal rather than rigorously empirical, but it lays the groundwork for further study and analysis of an important, yet rarely remarked on, aspect of employment morality and sport labor studies.

\section{The Precarity of Sport Work}

Workers who engage in part-time, insecure, and unprotected work are identified as precarious workers. The identification of an increase in precarious work has led to the recognition of a new global class of workers. "The Precariat" is a social class of people who suffer from precarity as they live in conditions of unpredictability and a lack of the kind of security integral to material or psychological welfare (Foti, 2017; Standing, 2014). Their lives are precarious because they have little or no job security. Those who are excluded by the traditional job protection and social security associated with traditional full-time labor arrangements are affected by the condition of precarity. They have few rights in the workplace. These precarious workers are the outsiders of the labor market as they are excluded from the Fordistera class compromise that provided the social safety net granted to previous generations. Their role in the service/information economy is essential, yet they have no say on labor relations or economic policy (Foti, 2017). Although analysis of the emerging precariat and labor precarity published recently is important (see Kalleberg \& Vallas, 2018; Standing, 2011), the present commentary focuses more on the nature of precarious work in sport events and the impact that the COVID-19 pandemic has had and will have on this type of worker and the people who engage in those jobs.

Sport work at the basic level is just that, work and not sport; and it is work that matters to those who do it. While working in sport is often romanticized, it is also gainful employment that provides a basic living for many in the United States. In order to understand the nature of precarious sport event work, briefly describing the nature of work, in general, is necessary. It is perhaps a truism to state that work matters in people's lives_-but it does and in several basic ways. Engaging in work provides workers with the obvious benefit of pay, which enables them to survive in modern market systems. However, work also has deeper level psychosocial meaning to individuals that goes beyond simply making a living. In the German Ideology (1845/1972), Karl Marx and Friedrich Engels saw individual expression and identity as coinciding with worker's production. Work offers a source of expression, identification, and satisfaction on individual and societal levels. Sport event work is no different. Identification and satisfaction matter, but there is another condition to be considered. That condition is affiliation with a sports team or a major event. The emotional attachment important to many sports fans gives sports organizations the ability to attract low-paid, hourly, part-time workers who may be willing to work for less with greater uncertainty because they revel in personal pride and social capital that they derive from working at the ballpark 81 times a year.

On a group level, work in sport can also allow for the fulfillment of a social contract (see Kochan, 1999) that commits individual members to engage as 
productive contributors to society. This social contract can be realized at the societal level, community level, or family group level. From the fulfillment of this social contract, the individual derives a sense of belonging and fulfillment, which increases self-respect and self-actualization. In many ways, sport event work has also become an identifier of social status, and levels of social identification are attached to the work one engages in. Although this last statement is a simplified overgeneralization, when examined through the paradigm of employed versus underemployed, or employed versus unemployed, or underemployed versus unemployed, those who have employed status generally enjoy higher social status. Sport work also offers an element of "cool," which potentially increases social status. Working with higher levels of uncertainty may be acceptable because the worker can identify with the team or be able to say they were present at the "big game." Work also offers a source of fulfillment through the development and use of skills, a source of identity and personal achievement and a source of structure. The COVID-19 pandemic upended any sort of structure in citizens' and workers' lives. Jobs in sport gain importance beyond the paycheck earned from working an event, but the loss of sense of self and social identification is part of the impact of being laid off. Workers often choose to work at events and games because of a sense of belonging and affiliation; losing sport event work opportunities damages that sense.

In the early 21 st century, we have seen a change in the structure of work. Work has been changing and so have the identifications and social/class structures surrounding it. In his book, The End of Work, Rifkin (2004) predicted sharp rises in global unemployment and underemployment. He posits that advancements in technology are rendering humans obsolete in many sectors of the global economy. As a result, new workers entering the labor pool will face either underemployment or unemployment. As technology changes and advances the mode of production, the need for human labor diminishes in many areas of economic life. Scarcity of full-time employment forces individuals in the labor market (and sport work is no different) to assemble a "portfolio of jobs" that offer little to no long-term economic security. The modern colloquialism for this type of worker would be "gig workers" (Kessler, 2018). Kessler broadly describes gig workers as those who work without any guarantee of steady hours or benefits. This phenomenon has been widely discussed in the fields of economics, labor studies, human resource management, and sociology since the early 1990s and has been assigned various and often interchangeable names, such as casual labor, flexible labor, precarious labor, precarity, hidden labor, and informalized labor (Arnold \& Bongiovi, 2013). This type of work is, by nature, insecure, uncertain, and unstable, with employees bearing the risk of work, as opposed to the employer or government, and receiving limited social benefits and legal protection (Kalleberg, 2009; Kalleberg \& Vallas, 2018). Regardless of the moniker employed and the romantic notion that once accompanied the idea of piecing together an existence through numerous sources, workers in the gig economy are thrust into higher levels of precarity than those in traditional full-time work. This includes the part-time front of house staff for public assembly facilities, including ushers, concessions workers, ticket takers, and security personnel who work in the sports events and venues space.

Sport organizations, like those in other industries, have strived to create operating models that provide maximum efficiencies and flexibility. Combined with technological advances, the quest for efficiency and flexibility has reshaped 
the landscape of work in the 21st century and moved models of employment away from the normalized full-time, regular, and defined work week that became the foundation of the Fordist era and replaced it with part-time, flexible, contingent, independent contractor, or other forms of work that fit the new just-in-time and flexible system.

Work in sports events and venues is by its very nature precarious. Standing (2014) posits that this concept of labor flexibility, or precarity, extends beyond the hiring routines of contemporary business organizations. For Standing, precarity exists when people lose their jobs, when they fear losing their jobs, and when they perceive themselves to lack employment alternatives. Precarity also exists within the realm of the job itself when work is unsafe or lacks collective representation. The situation that sport events workers find themselves in matches Standing's observations on precarity. Work only exists when events take place and is often hit or miss; many of the workers engage in numerous gig jobs (therefore compiling a portfolio of jobs), lack any collective bargaining unit to ensure fair play and treatment, and per the Exemption for Seasonal Amusement and Recreational Establishment Employees (of the U.S. Fair Labor Standards Act) are not eligible for overtime pay and other benefits. Systems of precarious work are not new. In fact, Kalleberg and Vallas (2018) suggested that until the end of the Great Depression in the United States, most jobs were precarious and pay unstable. It was not until the end of the labor movements and Roosevelt's New Deal in the 1930s that other benefits such as pensions and health insurance became common in the American workplace. The passage of U.S. labor laws (National Labor Relations Act, Fair Labor Standards Act, Title VII of the Civil Rights Act of 1964) related to wage and hours, minimum wage, and the right to collectively bargain greatly increased worker security; as previously mentioned, precarious work is, by definition, any work arrangement that creates conditions of instability, uncertainty, unpredictability, risk, and exploitation (Kalleberg, 2009). Mills (1951) observed the changes in the employer/employee dynamic, prognosticating that demand for worker specialization and deskilling would widen the gap in power and decision making and create workers detached from their vocation. Mills never uses the term "worker detachment," but it serves as a good description of the shift in power and subsequent change in worker identification. This is an important idea as we explore the concept of worker precarity in sport. Many of the current trends could be argued to center on systems of workplace preparation that accord power, worth, and selfidentification to those whom Mills would call the "power elite" at the expense of a new class of vulnerable laborers.

Additionally, Mills (1951) argued that there would be a rising level of education among the work force, which would create a credentialing crisis, referring in this connection to "surplus graduates" (p. 270) and the "management of ambition" (p. 285). This analysis has proven prescient in reference to the practices of management in sport venue and events operations. With approximately 480 undergraduate sport management programs in the United States, there is an abundant supply of people graduating with a dream of working in the industry, and, for many, working events is the way in. The internship requirements put in place by many universities further floods the supply of low-wage (and in some cases no wage) event workers.

It should be recognized that most sport organizations, by the nature of their business, are seasonal enterprises, with each sport having a distinct period in which 
their demand for workers increases. Outside of the sport product, venues host concerts and other entertainment spectacles that also draw demand for workers. As such, sport organizations are pulsating organizations (Hanlon \& Jago, 2000) that, rather than maintaining a steady labor force, fluctuate to meet the immediate demand for staffing. Within this type of organization, there may be three levels of employee: core employees (full time, part time, year round), peripheral (seasonal, part time, temporary), and distance workers (contract workers, specialists) (Atkinson, 1987). It is the peripheral and distance workers who make up the majority of the pulsated organization and who shoulder the highest level of precarity.

Pulsating organizations depend on precarious work and have profited from its use. It was never hidden; it operated in the public eye but was far from the public conscious. The pandemic has exposed the flaws and exploitation in the current labor model employed by the sport and events industry, and, for a brief moment, people cared about the person who brings our beer at an event or the usher who shows us to our seat. What most people are missing is that all the pandemic did, in the case of the NBA and National Hockey League, was bring the end of the employment agreement up a few weeks. Sure, some teams make the playoffs and extend the work opportunities but, in reality, this only adds to the precariousness of the work situation. No one knows for sure when the work will stop. The pulsating organization model succeeds from a financial and operational standpoint but it is severely flawed from a human relations view. As previously stated, it thrives on a market system that has put profit before people, it takes advantage of fan affiliation, emotional attachment, and social standing, and it preys on those (e.g., college students) who hope to secure career employment (via internships and part-time work) in the sport industry.

\section{The Future of Precarious Sport Work}

The change in the global economy has changed the outlook of work in general. The trends have been in favor of an increase in alternative work arrangements, that is, independent contractors, on-call workers, temporary workers, staffing agency workers, and other contract workers (Kalleberg \& Vallas, 2018). The share of such labor in the job market rose from $10.7 \%$ in 2005 to $17.2 \%$ in 2015 of all employment. There was an increase of nine million jobs with no increase in traditional full-time employment (Katz \& Krueger, 2019). The current pandemic may only further accelerate the shift to precarious work in the economy and, in some cases, result in the elimination of certain types of full-time work and possibly initiate a long-term shift in the sport event workers' labor patterns. In the aftermath of the sport shutdown, sport workers were left to wonder how their income would be affected.

Temporarily, the structure of work has changed for much of the workforce. Schooling at all levels from primary and secondary to higher education have resorted to remote delivery. Sport media have relied on replays of historical games, documentaries, and virtual competitions where esports coverage has thrived. Teleconferencing has made the office work transition almost seamless; sport event work continues to be on pause. The gig economy for grocery and essential items persists. The efficiency of technology-driven groceries, food, and other 
goods that can be shipped or delivered continues to thrive. The precarious worker can find work in delivery, shipping warehouses, and other jobs that have become essential work during the pandemic, while seeing their risk of transmission increase. Meanwhile, those in steady employment are able to stay home and work remotely. The demand in remote work seems to be increasing. The questions remain whether precarious event workers will return to work and whether they will even have the choice to return to their jobs due to the change in how spectator sport is delivered.

Different sports were impacted on different levels. The NBA and National Hockey League were close to wrapping up the regular season. MLB regular season had not begun, the MLS was only three games into the season, and the National Football League was in its off-season, with the regular season months away. The comparatively longer term work offered in venues by longer season leagues like MLB and MLS likely has had the biggest impact and created the highest level of uncertainty for workers in those sports. It has forced individuals who had relied on the longer seasons to find replacement work on a more urgent basis than in the past. Companies such as Amazon have been hiring laid off workers to help deal with the upswing in orders during the shutdown, and grocery store and drug store chains have been doing the same thing. But these, too, are precarious jobs. Although workers who have benefited from these opportunities, like those who are victims of layoffs, are not limited to sport workers, they are most certainly part of the same sort of vulnerable labor pool. It remains to be seen whether displaced sport workers will return to the venues once they open. Will college students take other paths and gain experience elsewhere? If sport event workers fail to return, the very model that exploited them will prove to be a major obstacle for the organizations that run sport events and venues.

\section{The Precarious Future of Spectator Sport Events}

Much is unknown about the impact of COVID-19 on society, let alone on the sports industry. It is difficult to know how the current crisis will affect the nature of sport event workers' jobs. These jobs are integral to the implementation of sporting events and serve as the foundation for many livelihoods. As restrictions are lifted on businesses and other facets of everyday life, sport in major venues will change in the short term. When games return, it is likely that they will, at first, be played in empty venues. If fans are allowed in, many will refuse to attend games without a vaccine widely available, or, at minimum, spectator capacities will be limited due to social distancing policies. The number of concessions workers, security guards, ushers, hospitality attendants, and other game day employees will be severely diminished. Those hourly workers who are not highly identified sport fans will likely find alternative work sources and, in some cases, leave the sport labor marketplace. COVID-19 has also put a premium on frontline work and the health implications of jobs where direct contact is unavoidable. Especially when collective bargaining is involved, it may be difficult to convince game day employees to return without safeguards. All 30 MLB teams' food workers are covered by unions, and it is unlikely that these workers will return to work without agreements that can ensure their health and safety. 
It is clear that the precarity of sport event workers is not new. However, the ability for much of the sport event jobs to exist also depends on whether the fans show up. The evidence is in public opinion. Sport, as we know it, will not return in full force in the short term in 2020. A late April Reuters/Ipsos poll showed that over half of Americans will not return to amusements such as sports events, movies, and concerts if they open before there is a vaccine (Carroll, 2020). If sport events are able to return to their previous level of spectator attendance and can be staffed at previous levels, the highly identified sport event worker may return. At this point in time, it will not be the market that decides; it will be advancement in a vaccine to ensure people can safely enjoy spectator sporting events again. Regardless of how this eventually plays out, the sport event worker's existence will continue to be precarious.

As previously stated, this scholarly commentary lays the groundwork for further study and analysis of an important, yet rarely remarked on, aspect of employment morality and sport labor studies. This is important research that should aim to develop a deeper understanding of the precarious situation that sport and event workers find themselves in. Sport (and other) organizations have been able to avoid, or shift away from, a paradigm of work that guaranteed security in favor of one that offers no stability and security. Why is this acceptable and why has it gone unchallenged? Furthermore, in the midst of a global pandemic, the plight and milieu of these precarious sport workers attracted little attention. Why was this not considered important enough to address? For those who attend sporting events, does the work and life situation of those who make events possible not matter as long as the game happens? Lastly, both the immediate and long-term impacts of the sport shutdown on sport event workers are not yet known. Will it continue to be ignored? At present, any outlook on the post COVID-19 world is largely speculative, with high levels of uncertainty. As we move toward the "new normal," the existence and impacts of precarious work in the sport and events industry can no longer be left unexamined on the periphery of academic, management, and policy discussion. It is a complex and very real phenomenon that cannot and should not be ignored.

\section{References}

Armour, N., Axon, R., Berkowitz, S., \& Schade, T. (2020, April 26). Owners pledged to pay workers when sports shut down, but many are being overlooked. USA TODAY. Retrieved from https://www.usatoday.com/story/sports/2020/04/26/coronavirus-ownerspledged-pay-workers-but-many-being-overlooked/3012573001/

Arnold, D., \& Bongiovi, J.R. (2013). Precarious, informalizing, and flexible work: Transforming concepts and understandings. American Behavioral Scientist, 57(3), 289-308. doi:10.1177/0002764212466239

Atkinson, J. (1987). Flexibility or fragmentation? The United Kingdom labor market in the eighties. Labour and Society, 12(1), 87-105.

Carroll, R. (2020, April 28). Most Americans to avoid sports, other live events before coronavirus vaccine: Reuters/Ipsos. Reuters. Retrieved from https://www.reuters.com/ article/us-health-coronavirus-usa-events/most-americans-to-avoid-sports-other-live-eventsbefore-coronavirus-vaccine-reuters-ipsos-idUSKCN22A2AK

Casselman, B. (2020, April 29). Worst Economy in a decade. What's next? 'Worst in our lifetime.' New York Times. Retrieved from https://www.nytimes.com/2020/04/29/business/ economy/us-gdp.html 
Foti, A. (2017). General theory of the precariat: Great recession, revolution, reaction. (Theory on Demand; No. 25). Amsterdam, The Netherlands: Institute of Network Cultures.

Hanlon, C., \& Jago, L. (2000). Pulsating sporting events: An organisational structure to optimise performance. In J. Allen, R. Harris, L. Jago, \& A. Veals (Eds.), Proceedings of Conference on Event Evaluation, Research and Education (pp. 93-105). Sydney, Australia: Australian Centre for Event Management.

Kalleberg, A.L. (2009). Precarious work, insecure workers: Employment relations in transition. American Sociological Review, 74(1), 1-22. doi:10.1177/000312240907400101

Kalleberg, A.L., \& Vallas, S.P. (2018). Probing precarious work: Theory, research, and politics. Research in the Sociology of Work, 31(1), 1-30.

Katz, L.F., \& Krueger, A.B. (2019). The rise and nature of alternative work arrangements in the United States, 1995-2015. ILR Review, 72(2), 382-416. doi:10.1177/0019793918820008

Kessler, S. (2018). Gigged: The end of the job and the future of work. New York, NY: St. Martin's Press.

Kochan, T.A. (1999). Reconstructing America's social contract in employment: The role of policy, institutions, and practices. Chicago-Kent Law Review, 75(1), 137-150.

Marx, K., Engels, F., In Arthur, C.J., \& Marx, K. (1845/1972). The German ideology. New York, NY: International Publishers.

McLeod, C.M., Holden, J.T., Hawzen, M.G., \& Chahardovali, T. (2019). Do influxes of atypical labor make sport event workers prone to exploitation? Sport Management Review, 22(4), 527-539. doi:10.1016/j.smr.2018.07.003

Mills, C.W. (1951). White collar: The American middle classes. New York, NY: Oxford University Press, Galaxy.

Rifkin, J. (2004). The end of work: The decline of the global labor force and the dawn of the post-market era. New York, NY: G.P. Putnam's Sons.

Standing, G. (2011). The precariat: The new dangerous class. London, UK: Bloomsbury Academic.

Standing, G. (2014). Understanding the precariat through labour and work. Development and Change, 45(5), 963-980.

Swartz, N.D., Hsu, T., \& Cohen, P. (2020, April 30). Stymied in seeking benefits, millions of unemployed go uncounted. The New York Times. Retrieved from https://www.nytimes. com/2020/04/30/business/economy/coronavirus-unemployment-claims.html 